\title{
PROPRIEDADES FÍSICAS DE UM LATOSSOLO BRUNO AFETADAS PELOS SISTEMAS PLANTIO DIRETO E PREPARO CONVENCIONAL ${ }^{(1)}$
}

\author{
F. S. COSTA (2), J . A. ALBUQUERQUE ${ }^{(3)}$, C. BAYER $^{(4)}$, \\ S. M. V. FONTOURA ${ }^{(5)} \&$ C. WOBETO(5)
}

\begin{abstract}
RESUMO
A qualidade física de solos agrícolas pode ser afetada pelo sistema de manejo, sendo a magnitude das alterações dependente do tempo de uso do solo e das condições edafoclimáticas. Neste estudo, avaliou-se o efeito de longo prazo (21 anos) dos sistemas de preparo convencional (PC) e plantio direto (PD) sobre propriedades físicas da camada de 0-0,2 $\mathrm{m}$ de um Latossolo Bruno alumínico câmbico (629 g kg-1 de argila), em Guarapuava (PR). Em relação à área sob mata nativa, contígua ao experimento e tomada como referência, o cultivo do solo em PC resultou não só no aumento da densidade global (Ds), na resistência do solo à penetração (RP) e na temperatura do solo, mas também na diminuição do diâmetro médio geométrico dos agregados (DMG). A adoção do sistema PD promoveu uma melhoria nas propriedades físicas do solo em comparação ao PC, evidenciada pela diminuição de $9 \%$ (de 1,08 para 0,99 $\mathrm{Mg} \mathrm{m}^{-3}$ ) na Ds em subsuperfície (0,1-0,2 m), de $13 \%$ (de 27,9 para 24,7 드) nas temperatura máximas (15 h), na camada de 0-0,05 m; e pelo aumento de $126 \%$ (de 1,6 para 3,7 mm) no DMG dos agregados na superfície do solo $(0-0,05 \mathrm{~m})$, e de $26 \%$ (de 0,38 $\mathrm{m}^{3} \mathrm{~m}^{-3}$ para $0,48 \mathrm{~m}^{3} \mathrm{~m}^{-3}$ ) no conteúdo de água volumétrica de 0-0,1 $\mathrm{m}$. Por outro lado, 0 PC e o PD não se diferenciaram quanto aos seus efeitos na porosidade do solo (total, macro e micro), na condutividade hidráulica saturada, na resistência do solo à penetração e no grau de floculação de argila. 0 rendimento das culturas de soja (18 safras) e milho (4 safras) foi, respectivamente, 42 e 22 \%superior em PD do que em PC, o que, possivelmente, reflete a melhoria na qualidade física do solo.
\end{abstract}

Termos de indexação: sistemas de manejo, qualidade do solo, produtividade de culturas, sustentabilidade.

\footnotetext{
(1) Parte da Tese de Mestrado do primeiro autor, apresentada ao PPG-Ciência do Solo da Universidade do Estado de Santa Catarina - UDESC. Recebido para publicação em janeiro de 2002 e aprovado em abril de 2003.

(2) Doutorando no PPG-Ciência do Solo da Universidade Federal do Rio Grande do Sul - UFRGS. Caixa Postal 776, CEP 90001-970 Porto Alegre (RS). E-mail: fal berni.costa@ufrgs.br

(3) Professor do Departamento de Solos da Universidade do Estado de Santa Catarina - UDESC. Av. Luiz de Camões 2090 Lages (SC). E-mail: a2ja@cav.udesc.br

(4) Professor do Departamento de Solos, UFRGS. Pesquisador do CNPq. E-mail: cimelio.bayer@ufrgs.br

(5) Pesquisador da Fundação Agrária de Pesquisa Agropecuária - FAPA. Colônia Vitória, Entre-Rios, Guarapuava (PR). E-mail: sandrav@agraria.com.br; cwoberto@agraria.com.br
} 


\title{
SUMMARY: PHYSICAL PROPERTIES OF A SOUTH BRAZILIAN OXISOL AS AFFECTED BY NO-TILLAGE AND CONVENTIONAL TILLAGE SYSTEMS
}

\begin{abstract}
Soil management affects thesoil physical quality, but the magnitude of thechanges is dependent of use time and regional edaphoclimatic conditions. The objective of this study was to evaluate the long-term ( $21 \mathrm{yr}$ ) effect of conventi onal tillage (CT) and no-tillage (NT) systems on somephysical properties in the $0.2 \mathrm{~m}$ top layer of an Oxisol from Paraná, southern Brazil. In comparison with an adjacent forest soil used as reference, the use of CT system increased thesoil bulk density, penetrometer resistanceand soil temperature; and decreased themean geometric diameter of soil aggregates Themain changes in soil attri butes by using NT in comparison with CT were: decrease in soil bulk density in subsurface layer (0.1$0.2 \mathrm{~m}$ ) from 1.08 to $0.99 \mathrm{Mg} \mathrm{m}^{-3}$; decrease in maximum soil temperature in the 0-0.05 m layer from 27.9 to 24.7 ㅇ; increase in mean geometric diameter of soil aggregates from 1.6 to $3.7 \mathrm{~mm}$ at 0-0.05 m layer; and increase in vol umetric soil water content in the $0-0.1 \mathrm{~m}$ layer from 0.38 to $0.48 \mathrm{~m}^{3} \mathrm{~m}^{-3}$. However, there were no differences between effects of tillage systems on soil porosity (total, macro and microporosity), saturated hydraulic conductivity, penetrometer resistance, and day flocculation degree Theamel ioration of physical properties in no-till ed soil may berelated to increases of $42 \%$ in soybean and $22 \%$ in corn yields in this conservation tillage system, in comparison with CT system.
\end{abstract}

Index terms: soil management systems, soil quality, crop productivity, sustainability.

\section{NTRODUÇÃO}

Uma das principais metas da pesquisa em manejo de solos é identificar e desenvolver sistemas de manejo desol o adaptados às condições edafod imáticas, sociais e culturais regionais. Do ponto de vista técnico, o sistema de manejo deve contribuir para a manutenção ou melhoria da qualidade do solo e do ambiente, bem como para a obtenção de adequadas produtividades das culturas a longo prazo.

A relação entre o manejo e a qualidade do solo pode ser avaliada pelo seu efeito nas propriedades físicas, químicas e biológicas do solo (Doran \& Parkin, 1994). Dentreas propriedades físicas do solo, a estrutura é uma propriedade sensível ao manejo, cuja qualidade podeser analisada segundo variáveis relacionadas com sua forma (Albuquerque et al., 1995) e, ou, com sua estabilidade (Campos et al., 1995). O efeito do manejo sobre as propriedades físicas do solo é dependente da sua textura e mineralogia, as quais influenciam a resistência ea resiliência do solo a determinada prática agrícola (Seybol d et al., 1999).

Geralmente, as práticas de manejo têm maior impacto sobre as propriedades físicas de solos arenosos do que de solos argilosos. Nesse sentido, Silva \& Mielniczuk (1997) verificaram redução do diâmetro médio ponderado (DMP) dos agregados de $71 \%$ num Argissolo Vermel ho ( $220 \mathrm{~g} \mathrm{~kg}^{-1}$ de argila) e de $47 \%$ num Latossolo Roxo (680 $\mathrm{g} \mathrm{kg}^{-1}$ argila), quando passaram de uma condição de campo nativo para preparo convencional com culturas anuais e lavração e gradagem. Por outro lado, os autores verificaram um aumento da estabilidade de agregados de ambos os sol os quando submetidos ao sistema plantiodireto. O DMP dos agregados passou de 0,61 mm, no Argissolo, e de 1,76 mm, no Latossolo, em preparo convencional, para valores de 0,91 e 1,90 mm, respectivamente, em plantio direto. E m termos relativos, o aumento ocorrido na estabilidade de agregados do solo em plantio direto foi de 49 e $8 \%$, respectivamente, no Argissolo francoarenoso e no Latossolo argiloso.

Além da classe de solo, as condições climáticas, os sistemas de cultura utilizados, o tempo de uso dos diferentes sistemas de manejo e a condição de umi dade do sol o em que são realizadas as operações de campo determinam a magnitude dos efeitos do manejo sobre as propriedades físicas do solo. Isso explica, em parte, os diferentes resultados obtidos quanto ao efeito dos sistemas de preparo convencional e plantio direto na densidade do solo, na porosidade e na resistência do solo à penetração (Abrão et al., 1979; Eltz et al., 1989; Bertol et al., 2000). Por outro lado, normalmente tem sido observado no solo em plantio direto um aumento no conteúdo de água, (Salton \& Mielniczuk, 1995), na condutividade hidráulica saturada (Sidiras et al., 1984) e na estabilidade de agregados do solo (Carpenedo \& Mielniczuk, 1990), bem como uma diminuição das temperaturas máximas do solo (Bragagnollo \& Mielniczuk, 1990).

O objetivo deste estudo foi verificar os efeitos de longo prazo (21 anos) dos sistemas de plantio direto e preparo convencional sobre al gumas propriedades físicas de um Latossolo Bruno alumínico câmbico. O rendimento acumulado de grãos das culturas do 
milho e da soja também foi avaliado e interpretado em relação às alterações nas propriedades físicas do solo.

\section{MATERIAL E MÉTODOS}

O estudo foi realizado em experimento de longa duração (21 anos), no Campo Experimental da Fundação Agrária de Pesquisa Agropecuária - FAPA ( 25 으 'S; 51 29 'W), Colônia de Entre Rios, Guarapuava (PR). O clima da região é do tipo $\mathrm{Cfb}$, segundo classificação climática de Köeppen, sem estação seca durante o ano e com geadas freqüentes e severas no inverno. A preci pitação média anual é de $2.022 \mathrm{~mm}$, ea temperatura média anual de 16,5 ${ }^{\circ} \mathrm{C}$ (J aster et al., 1993). O solo da área experimental é um Latossolo Bruno alumínico câmbico, com horizonte A proeminente, relevo suave ondulado e substrato basal to (EMBRAPA, 1999), com classe textural variando de argilosa a muito argilosa (Quadro 1). Na fração argila do solo, ocorre predomínio de caulinita e gibsita e, em menor quantidade, minerais 2:1 com hidróxi-Al nas entrecamadas, hematita e goethita (Costa, 2001).

A área em estudo tem como vegetação clímax a mata nativa (Maack, 1948). Com a sua remoção, em aproximadamente 1910-1920, a mata deu lugar ao campo natural, composto por espécies nativas, principalmente gramíneas. A partir de 1950, o solo foi cultivado com arroz (Oryza sativa) e trigo (Triticum aestivum), durante 12 anos no sistema de preparo convencional, com lavração e gradagens. De 1962 a 1968, a área foi utilizada com pastagem mel horada para o gado leiteiro. Nos anos seguintes, até 1978, o sol o foi cultivado na sucessão trigo/soja (Glicinemax) em preparo convencional, com aração egradagens. No inverno de 1978, a área foi corrigida com 1,5 Mg ha-1 de cal cário e $300 \mathrm{~kg} \mathrm{ha}^{-1}$ de Escória de Thomas, semeando-se soja na primavera-verão como a primeira cultura do experimento. No quadro 1, é apresentada a caracterização química e granulométrica do solo antes do início do experimento e 21 anos após a instalação do experimento; uma área de mata nativa, contígua à área do experimento, foi utilizada como referência da condição original do solo da área experimental .

O experimento, em delineamento de blocos ao acaso, com três repetições, foi constituído pel os sistemas de PC e PD, aplicados na instalação das culturas de inverno e de primavera-verão. O sistema PC consistiu numa aração com arado de discos, na profundidade de até $0,2 \mathrm{~m}$, eduas gradagens, sendo uma com grade niveladora e outra com grade de dentes. O sistema PD consistiu no revol vimento do solo apenas na linha de semeadura e foi realizado com máquinas semeadora-adubadoras adaptadas para esse sistema. No período de 1978-1985, cultivou-se a sucessão trigo/soja, e de 1986 a 1999, utilizou-se um sistema de rotação de culturas envolvendo aveia branca (Avena sativa), trigo,

Quadro 1. Caracterização química e granulométrica de um Latossolo Bruno alumínico câmbico antes do início e 21 anos depois do experimento, em preparo convencional e plantio direto, e de uma área de mata nativa adjacente. Guarapuava (PR)

\begin{tabular}{|c|c|c|c|c|c|c|c|c|c|}
\hline Profundidade & $\mathbf{C a}$ & Mg & $\mathbf{K}$ & Al & $\mathbf{p H}-\mathrm{H}_{2} \mathrm{O}$ & $\mathrm{CO}^{(2)}$ & Argila & Silte & Areia \\
\hline $\mathrm{m}$ & \multicolumn{5}{|c|}{$-\mathrm{cmol}_{\mathrm{c}} \mathrm{kg}^{-1}$} & \multicolumn{4}{|c|}{$\mathrm{g} \mathrm{kg}^{-1}$} \\
\hline \multicolumn{10}{|c|}{ Início do experimento (1978) } \\
\hline $0-0,2$ & $5,7^{(1)}$ & - & 0,25 & 0,15 & 5,5 & 28 & - & - & - \\
\hline \multicolumn{10}{|c|}{ Após 21 anos de realização do experimento (2000) } \\
\hline \multicolumn{10}{|c|}{ Preparo convencional } \\
\hline $0-0,05$ & 1,6 & 0,3 & 0,41 & 1,0 & 5,1 & 34 & 595 & 329 & 76 \\
\hline $0,05-0,1$ & 1,8 & 0,4 & 0,41 & 1,0 & 5,1 & 34 & 573 & 351 & 76 \\
\hline $0,1-0,2$ & 1,9 & 0,4 & 0,40 & 1,0 & 5,2 & 34 & 671 & 254 & 75 \\
\hline \multicolumn{10}{|c|}{ Plantio direto } \\
\hline $0-0,05$ & 3,1 & 0,7 & 0,70 & 1,2 & 4,9 & 44 & 559 & 382 & 59 \\
\hline $0,05-0,1$ & 1,5 & 0,3 & 0,30 & 1,9 & 4,8 & 36 & 596 & 337 & 67 \\
\hline $0,1-0,2$ & 1,4 & 0,3 & 0,24 & 1,5 & 5,0 & 34 & 608 & 326 & 66 \\
\hline \multicolumn{10}{|c|}{ Sob vegetação original (mata nativa) } \\
\hline $0-0,05$ & 4,4 & 1,9 & 0,40 & 1,8 & 4,8 & 48 & 670 & 262 & 67 \\
\hline $0,05-0,1$ & 1,1 & 0,7 & 0,20 & 2,7 & 4,8 & 34 & 606 & 311 & 82 \\
\hline $0,1-0,2$ & 0,6 & 0,4 & 0,16 & 3,4 & 4,8 & 29 & 695 & 225 & 81 \\
\hline
\end{tabular}

${ }^{(1)} \mathrm{Ca}+\mathrm{Mg} .{ }^{(2)}$ Carbono orgânico. 
cevada (Hordeum vulgare), ervilhaca peluda (Vicia Vilosa), nabo forrageiro (Raphanus raphanistrum), soja e milho (Zea mays). A rotação de culturas foi a mesma em todos os sistemas de manejo do solo, eas operações de apl icação de defensivos e col heita foram real izadas com equi pamentos utilizados em lavouras comerciais, obedecendo aos mesmos critérios técnicos destas. O manejo das plantas de cobertura foi feito por dessecação com herbicidas.

As propriedades físicas do solo foram avaliadas em janeiro de 2000, durante o desenvolvimento da cultura do milho. Três subamostras foram coletadas manualmente, com auxílio de espátula, nas profundidades de 0-0,05, 0,05-0,1 e 0,1-0,2 m. A col eta de amostras de sol o com estrutura preservada foi realizada com anéis metálicos $(54 \times 50 \mathrm{~mm})$ nas mesmas camadas de solo. A resistência do solo in situ foi avaliada com auxílio de um penetrômetro de bolso (Bradford, 1986) marca Humboldt, sendo realizadas quatroleituras por camada e os resultados expressos em M Pa. Tanto a col eta das amostras de solo como a avaliação da resistência do solo foram realizadas em trincheiras de 0,5 ×0,5 ×0,5 m, abertas manual mente.

Nas amostras de sol o com estrutura preservada, foram determinadas, a macroporosidade, pelo método da mesa de tensão (EMBRAPA, 1997), a condutividade hidráulica saturada, pel o método do permeâmetro de carga constante (Klute \& Dirksen, 1986), e a densidade do solo, pelo método do anel volumétrico (Blake\& Hartge, 1986). A partir dos valores de densidade do solo e da densidade de partícula, determinados pelo método do balão volumétrico (EMBRAPA, 1997), calculou-se a porosidadetotal. A microporosidadefoi calculada pela diferença entre a porosidade total e a macroporosidade. A estabilidade de agregados em água foi mensurada conforme Kemper \& Chepil (1965) e representada pelo diâmetro médio geométrico (DMG) dos agregados em milímetro (mm).

A temperatura do solo foi determinada a $0,05 \mathrm{~m}$ de profundidade nos dias 19 e 20 dejaneiro de 2000 , utilizando-se geotermômetros com precisão de $0,2{ }^{\circ} \mathrm{C}$ ( ackson \& Taylor, 1986), em apenas uma repetição nas áreas de mata, PC e PD, por causa da limitação de geotermômetros. A leitura da temperatura do sol o foi horária, das nove às quinze horas, estando o sol o sob a cultura do milho, no estádio de grãoleitoso. No verão seguinte $(16,20,23$ e 27 de novembro e 03 e 06 de dezembro de 2000), o conteúdo deágua do sol o foi avaliado nas camadas de 0-0,1 e0,1-0,2 m, durante o desenvolvimento da cultura da soja. As amostras foram secas em estufa a $105^{\circ} \mathrm{C}$ até peso constante, e calculada a umidade vol umétrica. O armazenamento deágua $\left(\mathrm{m}^{3}\right)$ nas camadas amostradas foi calculado a partir da umidade vol umétrica $\left(\mathrm{m}^{3} \mathrm{~m}^{-3}\right)$ do solo e da espessura da camada (m).

Durante o período experimental, avaliou-se o rendimento de 18 safras de soja e de quatro safras de milho. A col heita das culturas foi realizada com automotriz numa área útil de $800 \mathrm{~m}^{2}$ (8 x $\left.100 \mathrm{~m}\right)$, ou seja, excluindo-se $2 \mathrm{~m}$ de cada lado da parcela experimental. A grande área útil avaliada contribuiu para a obtenção de baixos coeficientes de variação nos dados de rendimento (4 a 6 \%) durante o período experimental. Rendimentos acumulados das culturas foram cal culados com base na umidade de grão de $13 \%$.

Os efeitos dos sistemas de manejo de solo sobre as propriedades físicas for am avaliados pela análise de variância segundo o delineamento de blocos casualizados, individualmente por camada de solo. A área de mata não foi incluída na análiseestatística por não atender aos pressupostos do respectivo delineamento experimental. A diferença entre médias de tratamentos foi avaliada pelo teste de Tukey, a $5 \%$. Os resultados detemperatura do solo e de rendimento de soja e de milho não foram analisados estatisticamente, visto que a temperatura do solo foi determinada em apenas uma repetição dos tratamentos, e apenas os rendimentos médios das três repeti ções, do período 1978-1987, encontramse disponíveis.

\section{RESULTADOS E DISCUSSÃO}

\section{Densidade do solo}

Em relação ao solo sob mata, houve uma tendência de incremento na densidade do solo em todas as camadas, tanto no PC quanto no PD (Quadro 2). I sso demonstra que o uso do solo para fins agrícolas, independentemente do sistema de manejo utilizado, promove alterações nas suas propriedades físicas. A densidade não foi estatisticamente diferente entre os sistemas de manejo nas camadas de 0-0,05 e 0,05-0,1 m. É possível que a maior densidade do solo sob PC em relação ao PD na camada de 0,1-0,2 m seja decorrente da transmissão da pressão realizada na superfície do solo pelas máquinas e implementos, pela compressão exercida pela lâmina dos discos do arado, bem como do pneu do trator rodando no sulco de aração naquele sistema.

A evolução temporal da densi dade do solo após 8 (em 1986) e 21 anos (em 2000) da utilização dos sistemas de PC e PD pode ser visualizada na figura 1. No solo sob PC, houve incremento da densidade do sol o de 1986 para 2000, indicando que, embora práticas mitigadoras do processo de degradação física do solo, como rotação de culturas e manutenção dos resíduos culturais no solo, tenham sido adotadas, a degradação física do solo parece estar acentuando-seaol ongo do tempo. Por sua vez, no solo sob PD, houve tendência de aumento na densidade apenas na camada superficial (0-0,05 m) de 1986 a 2000, enquanto, nas demais camadas, 
houve redução da densidade do solo neste período. Enquanto o aumento de densidade em superfície pode ser devido ao trânsito de máquinas e, ou, ao adensamentonatural, a diminuiçãoem subsuperfície indica uma melhoria na qualidade física do solo decorrente possivelmente da atividade da fauna edáfica e de raízes, as quais atuam na formação de canais (bioporos). Estes resultados são semelhantes aos obtidos por Al buquerque et al. (1995) e Bertol et al. (2000), mas discordam dos apresentados por Abrão et al . (1979), que verificaram maior densidade do solo em subsuperfície sob plantio direto.

Além da classe de solo, a condição de umi dade de solo, na qual são real izadas as operações de preparo, semeadura, tratamentos fitossanitários e col heita, é fundamental no comportamento da densidade do solo em diferentes sistemas de manejo, os quais provavelmente auxiliam a explicar os resultados obtidos em diferentes estudos. Adicionalmente, o tempo de utilização dos sistemas de manejo também é uma variável importante a ser considerada e ressalta a importância dos experimentos de longa duração na avaliação do efeito do manejo sobre a qualidade do solo.

\section{Porosi dade total, microporosidade e macropo- rosidade}

A porosidade total (PT) do solo variou de 0,59 a $0,64 \mathrm{~m}^{3} \mathrm{~m}^{-3}$, com a mata e os sistemas de manejo do sol o apresentando val ores semel hantes (Quadro 2). A menor PT do solo sob PC em relação ao PD na camada de 0,1-0,2 $\mathrm{m}$ pode indicar presença de compactação subsuperficial no solo em PC. A microporosidadee a macroporosidade não diferiram estatisticamente entre os sistemas de manejo e,

DENSIDADE DO SOLO, $\mathrm{Mg} \mathrm{m}^{-3}$

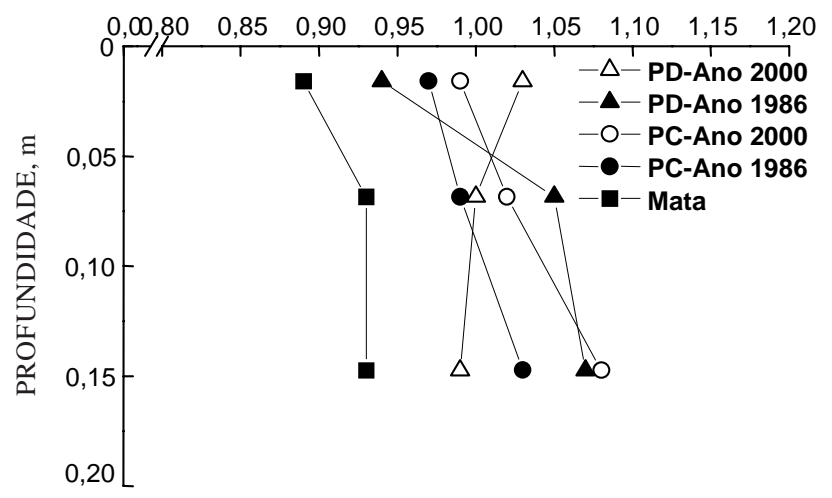

Figura 1. Evolução temporal da densidade de um Latossolo Bruno alumínico câmbico aos 8 anos (1986) e aos 21 anos (2000) de cultivo com sistemas de preparo convencional e plantio direto, em comparação ao solo sob mata. Guarapuava, PR. Os resultados referentes ao ano de 1986 foram obtidos em E ltz et al. (1989). praticamente, não apresentaram evidências de terem sido afetadas pelos sistemas em relação à mata. A mobilização do solo sob PC duas vezes ao ano pode estar relacionada com os valores semel hantes demacroporosi dade em relação à mata, principal mentenas camadas de 0-0,05 e 0,05-0,1 m. Entretanto, tanto na mata como nos sistemas de manejo, a macroporosidade, ou porosidade de aeração, foi superior ao mínimo considerado restritivo ao desenvol vimento radicular $\left(0,10 \mathrm{~m}^{3} \mathrm{~m}^{-3}\right)$ (Vomocil \& Flocker, 1961), embora esse val or limite dependa do tipo de planta e do nível de atividade biológica do solo (Gupta et al., 1989), entre outros fatores. Pequenas reduções na macroporosidadeem sol os sob PD também foram observadas por Tormena et al. (1998).

\section{Condutividade hidráulica saturada}

A condutividade hidráulica saturada (Ks) (Quadro 2), segundo limites propostos por Klute \& Dirksen (1986), foi baixa em todas camadas dos sistemas de uso e manejo do solo, apresentando coeficiente de variação de 75 a 152 \% entre repetições, concordando com a grande variabilidade desta determinação obtida por outros autores (Van Es et al., 1999). Provavel mente, devido aos altos valores de coeficiente de variação, a Ks não foi diferente estatisticamente entre os sistemas de manejo do solo. Contudo, a tendência de redução dos valores de Ks com o aumento da profundidade do sol o no PC, e aumento no solo em PD, possivel mente reflita o efeito dos sistemas de preparo sobre a densidade e por osidade do perfil do solo (Quadro 2).

\section{Resistência do solo à penetração}

A resistência do solo à penetração nas áreas de mata edesistemas demanejovariou de0,51 x 10-1 $\mathrm{MPa}$,

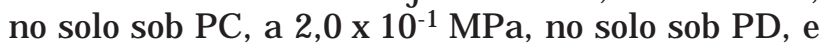
não foi afetada significativamente pel os sistemas de manejo (Figura 2a). Apesar disso, o solo sob PD apresentou os maiores valores absolutos de resistência do solo à penetração em todas as camadas. O maior conteúdo de água no sol o sob PD (0-0,05 e 0,05-0,1 m) no momento da coleta das amostras em relaçãoaoPC (Quadro 2), o qual poderia contribuir para uma menor resistência do solo ao penetrômetro, pareceindicar a possibilidade de uma compactação superficial no solo sob PD. Entretanto, esse efeito somente foi significativo pelo teste de Tukey a $7 \%$, decorrente do al to coeficiente de variação (42 a 67 \%) da resistência do solo à penetração.

\section{Grau de floculação}

O grau de floculação (GF) não foi afetado significativamente pel os sistemas de uso e manejo do solo em todas as camadas (Figura 2b). A partir dos maiores teores de cátions trocáveis, sobretudo na camada de 0-0,05 m (Quadro 1), era esperada uma maior floculação da argila no solo sob mata, o que, entretanto, não ocorreu. Outros fatores 
Quadro 2. Densidade do solo (Ds), porosidade total (PT), microporosidade (Mi), macroporosidade (Ma), umi dade volumétrica (Uv) e condutividade hidráulica saturada (Ks) de um Latossolo Bruno alumínico câmbico sob mata natural e 21 anos sob preparo convencional e plantio direto. Guarapuava (PR)

\begin{tabular}{|c|c|c|c|c|c|c|}
\hline Profundidade & Ds & PT & Mi & Ma & Uv & Ks \\
\hline \multirow[t]{2}{*}{$\mathrm{m}$} & $\mathrm{Mg} \mathrm{m}^{-3}$ & \multicolumn{4}{|c|}{$m^{3} m^{-3}$} & $\mathrm{~cm} \mathrm{~h}^{-1}$ \\
\hline & \multicolumn{6}{|c|}{ Mata nativa } \\
\hline $0-0,05$ & 0,89 & 0,64 & 0,44 & 0,20 & 0,34 & 13,3 \\
\hline $0,05-0,1$ & 0,93 & 0,63 & 0,46 & 0,17 & 0,37 & 3,5 \\
\hline \multirow[t]{2}{*}{$0,1-0,2$} & 0,93 & 0,63 & 0,46 & 0,17 & 0,37 & 3,4 \\
\hline & \multicolumn{6}{|c|}{ Preparo convencional } \\
\hline $0-0,05$ & $0,99 a$ & $0,64 a$ & $0,43 a$ & $0,21 a$ & $0,35 \mathrm{~b}$ & $8,9 a$ \\
\hline $0,05-0,1$ & $1,02 \mathrm{a}$ & 0,61 a & $0,42 \mathrm{a}$ & $0,19 a$ & $0,38 \mathrm{~b}$ & $13,4 \mathrm{a}$ \\
\hline \multirow[t]{2}{*}{$0,1-0,2$} & $1,08 \mathrm{a}$ & $0,59 \mathrm{~b}$ & $0,46 a$ & $0,13 a$ & $0,42 a$ & $1,6 a$ \\
\hline & \multicolumn{6}{|c|}{ Plantio direto } \\
\hline $0-0,05$ & $1,03 a$ & $0,60 a$ & $0,45 a$ & $0,15 a$ & $0,40 a$ & $4,4 \mathrm{a}$ \\
\hline $0,05-0,1$ & $1,00 \mathrm{a}$ & $0,61 \mathrm{a}$ & $0,45 a$ & $0,16 a$ & $0,41 a$ & $4,4 a$ \\
\hline $0,1-0,2$ & $0,99 \mathrm{~b}$ & $0,62 \mathrm{a}$ & $0,47 a$ & $0,15 a$ & $0,43 a$ & $11,3 a$ \\
\hline
\end{tabular}

Médias de sistemas de preparo, em cada camada de solo, seguidas de letras iguais não diferem significativamente pelo teste de Tukey a $5 \%$. Os valores referentes ao solo de mata não foram analisados estatisticamente.

biológicos, tais como: a maior atividade bacteriana, decorrente da menor acidez do solo (De Boer \& Kowalchuk, 2001), e alterações na qualidade da matéria orgânica (Hu et al., 1997) podem ser responsáveis pela menor dispersão de argila, em valor absoluto, na camada de 0-0,05 $\mathrm{m}$ do solo cultivado em comparação ao sol o sob mata.

\section{Estabilidade de agregados}

O maior DMG dos agregados foi observado na camada superficial do solo sob PD $(3,7 \mathrm{~mm})$, em comparação ao solo sob PC (1,6 mm), indicando um efeito positivo do não-revol vimento do sol o e acúmulo de resíduos vegetais na superfície sobre a estabilidade de agregados (Figura 2c). Nas demais camadas do solo, as diferenças no DMG dos agregados foram menores entre os sistemas de manejo de solo, com o PC apresentando maior DMG na camada subsuperficial (0,1-0,2 m). E feitos semel hantes do PD no aumento da estabilidade de agregados têm sido verificados em Argissolos (Albuquerque et al., 1994) e Latossolos (Campos et al., 1995) do Sul do Brasil. Segundo Silva \& Mielniczuk (1997), a magnitude das alterações é dependente da textura e mineralogia do solo. Altos teores de argila e predominância de minerais de carga variável caracterizam, geralmente, solos com mai or resistência às al terações físicas resultantes do manejo, em relação, principalmente, a solos arenosos.

\section{Temperatura do solo}

A temperatura e o regime térmico do solo dependem da sua cobertura superficial, com vegetação ou resíduos, e do conteúdo de água, além
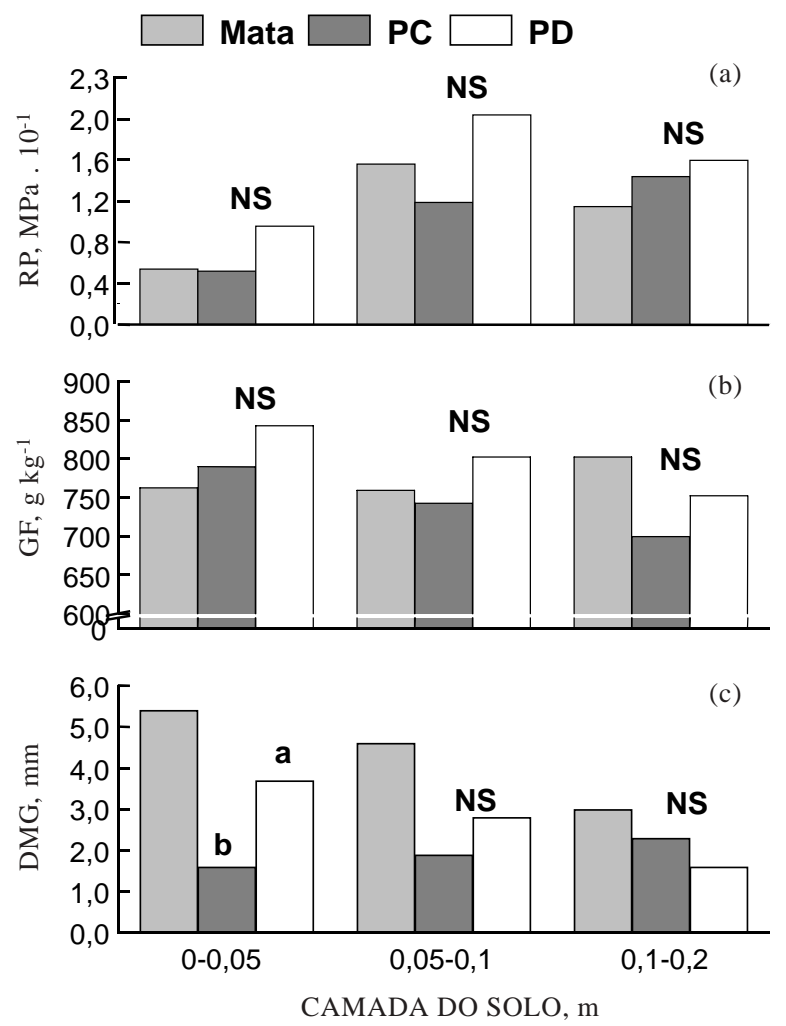

Figura 2. Resistência do solo à penetração - RP (a), grau de floculação de argi la - GF (b) e diâmetro médio geométrico de agregados - DMG (c) em diferentes camadas de um Latossolo Bruno alumínico câmbico sob mata, preparo convencional (PC) e plantio direto (PD). Guarapuava, PR. Letras diferentes, em cada profundidade, indicam diferença significativa pelo teste deTukey, a $5 \%$ NS = não-significativo. 
da intensidade e duração da radiação solar (Hillel, 1998). Nesteestudo, o comportamento da temperatura do solo foi semelhante nos dois dias de avaliação, com o sol o sob PC apresentando sempre as maiores temperaturas, o solo sob PD com valores intermediários, e o solo de mata com os menores valores (Figura 3). A temperatura do solo, no dia 19/01, alcançou 29,5 ㄷ no solo sob preparo convencional, enquanto, no sol o em plantio direto, a temperatura máxima foi de $25,9 \stackrel{\circ}{ } \mathrm{C}$. Na média dos dois dias avaliados, a temperatura máxima do solo em PC foi aproximadamente $5^{\circ} \mathrm{C}$ mais alta do que no solo em PD. A menor temperatura do solo em PD pode ser conseqüência, além da cobertura superficial do solo pel os resíduos vegetais da cultura anterior, à sua maior umidade volumétrica na camada superficial (Figura 4). O maior conteúdo de água no sol o em PD também contribuiu para a diminuição da amplitude térmica do solo de $7,4^{\circ} \mathrm{C}$, no PC, para $4,4 \stackrel{\circ}{ } \mathrm{C}$, no PD.

\section{Conteúdo de água no solo}

O solo em PD apresentou maior umidade volumétrica do que o solo em PC na camada de 0$0,1 \mathrm{~m}$ (Figura 4). Na camada de 0,1-0,2 m, a umidade do solo não diferiu entre os sistemas de manejo. Dois fatores principais podem ter contribuído para a maior umidade na camada superficial dosolo em PD: a maior infiltração deágua no solo, decorrente da não-formação de selo superficial (Dexter, 1988), e a menor evaporação de água, decorrente da cobertura do solo por resíduos (Salton \& Mielniczuk, 1995). Bragagnolo \& Mielniczuk (1990), na região da Depressão Central do Rio Grande do Sul, determinaram uma diminuição na evaporação de água de 2,64 mm dia-1, em solo descoberto, para $1,22 \mathrm{~mm} \mathrm{dia}^{-1}$, em solo

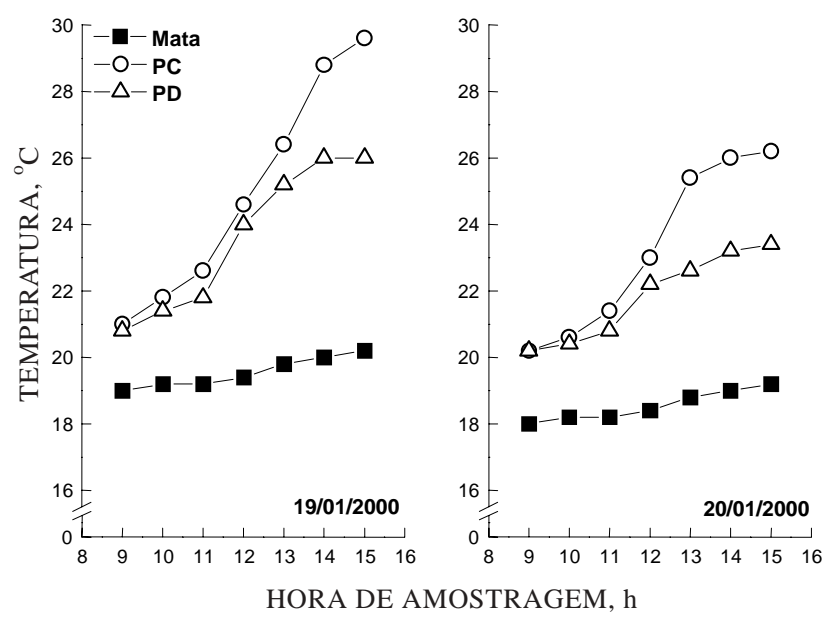

Figura 3. Temperatura do solo $(0-0,05 \mathrm{~m})$ de um Latossolo Bruno alumínico câmbico sob mata, preparo convencional (PC) e plantio direto (PD) aos 19 e 20 dias de janeiro de 2000. Guarapuava (PR).

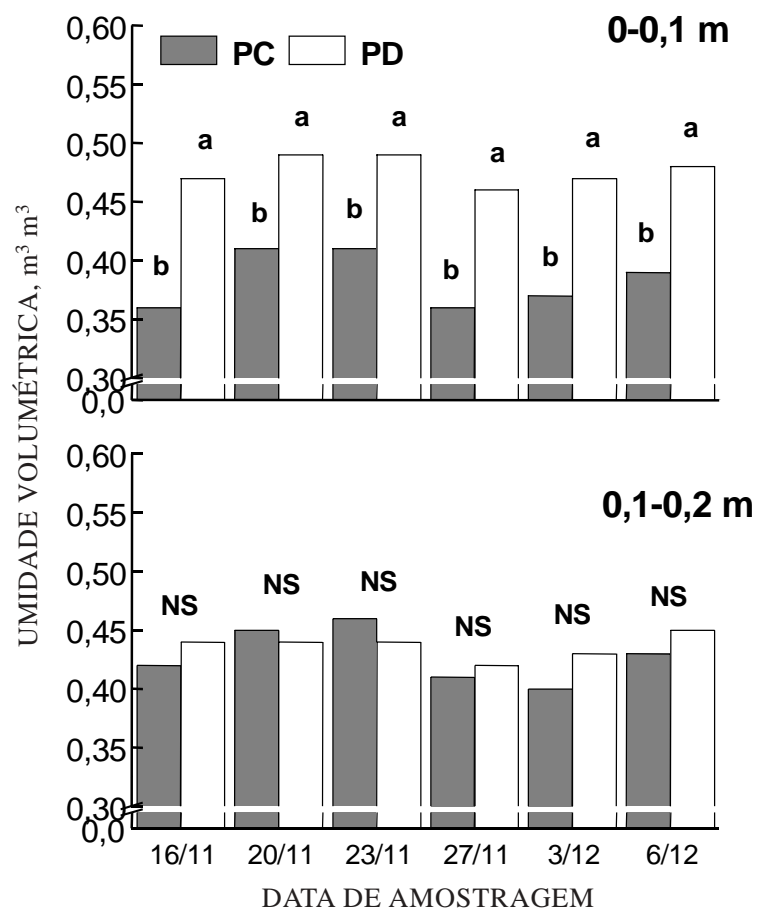

Figura 4. Umidade volumétrica de um Latossolo Bruno alumínico câmbico sob preparo convencional (PC) e plantio direto (PD) nas camadas de 0-0,1 e 0,1-0,2 m. Guarapuava (PR). Letras di ferentes, em cada data de amostragem, indicam diferença significativa pelo teste de Tukey, a $5 \%$ NS = não-significativo.

coberto por 7,5 t ha-1 de palha de trigo. Como conseqüência da menor evaporação, os autores verificaram que o solo coberto apresentou sempre mai or umi dade volumétrica do que o solo descoberto.

O armazenamento deágua na camada de 0-0,2 m foi $99 \mathrm{~m}^{3} \mathrm{ha}^{-1}$ superior no solo sob PD $\left(913 \mathrm{~m}^{3}\right)$ do queem PC (814 $\left.\mathrm{m}^{3}\right)$. Pressupondo que onível crítico inferior de disponibilidade deágua (ponto de murcha permanente) seja determinado pela textura e mineralogia do solo e, portanto, pouco influenciado pel o manejo, o maior conteúdo de água no solo sob PD indica maior disponibilidade hídrica para as culturas.

\section{Rendimento de grãos de soja e milho}

As culturas da soja (18 safras) e do milho (4 safras) apresentaram um rendimento de grãos acumulado 42 e $22 \%$ maiores no sistema PD do que no PC, respectivamente (Quadro 3). Os maiores rendimentos das culturas no sistema PD em comparação ao PC indicam que, no mínimo, nenhum fator físico está restringindo o desenvolvimento do sistema radicular das culturas no solo sob PD, há 21 anos sem revolvimento. Esses resultados são importantes, visto que foram obtidos num experimento de longa duração, com as operações de 
Quadro 3. Rendimento de grãos de milho e soja em preparo convencional e plantio direto em um Latossolo Bruno alumínico câmbico. Guarapuava (PR)

\begin{tabular}{|c|c|c|c|c|c|c|}
\hline \multirow{3}{*}{ Cultura } & \multirow{3}{*}{ No safra } & \multicolumn{4}{|c|}{ Rendimento } & \multirow{3}{*}{ PD/PC } \\
\hline & & \multicolumn{2}{|c|}{ Médio } & \multicolumn{2}{|c|}{ Acumulado } & \\
\hline & & PC & PD & PC & PD & \\
\hline & & \multicolumn{4}{|c|}{ - Mg ha-1 } & \\
\hline Soja & 18 & 1,44 & 2,06 & 26,0 & 37,0 & 1,42 \\
\hline Milho & 4 & 6,75 & 8,25 & 27,0 & 33,0 & 1,22 \\
\hline
\end{tabular}

Rendimento de grãos não foram submetidos à análise estatística porque não se dispõe dos resultados referentes às repetições experimentais do período inicial do experimento (1978-1987).

preparo do solo, tratos culturais e controles fitossanitários realizados com implementos e critérios de lavouras comerciais. Desta forma, os resultados obtidos demonstram que, para este L atossol o Bruno, havendo o cuidado de realizar-seo trânsito de máquinas em condições adequadas de umidade do solo, não ocorrem problemas com compactação e, portanto, não há necessidade de revolvêlo periodicamente.

Considerando a não-ocorrência de fator químico limitante ao desenvol vimento vegetal no sol o em PC (Ciotta, 2001), é possível que o regime hídrico mais favorável no solo sob PD (Figura 4) tenha sido um fator importante para os maiores rendimentos do milho e da soja no sistema PD, em comparação ao $P C$. Aliadas à maior umidade volumétrica, as temperaturas mais amenas do sol o sob PD (Figura 3) podem ser responsáveis pel os mai ores rendimentos, principalmente da cultura da soja, cuja temperatura ideal durante o seu ciclo é em torno de 20-25 ${ }^{\circ} \mathrm{C}$. Assim, as temperaturas de até $25{ }^{\circ} \mathrm{C}$ verificadas na camada superficial (0-0,05 m) do sol o sob PD podem ter efeito favorável ao rendimento de grãos de soja, em comparação ao solo em PC, no qual as temperaturas foram aproximadamente $3 \stackrel{\circ}{\circ}$ superiores.

\section{CONCLUSÕES}

1. O sistema de preparo convencional degradou as propriedades relacionadas com a forma e com a estabilidade da estrutura do sol o em relação à mata nativa, indicadas pelo aumento da densidade do solo e da resistência do solo à penetração e pela diminuição da estabilidade de agregados.

2. O solo em plantio direto apresentou mel hores condições estruturais, evidenciadas principalmente pela redução da densi dade do sol o em subsuperfície e pelo aumento da estabilidade de agregados na camada superficial do solo.
3. O solo sob plantio direto apresentou menor temperatura e maior umidade volumétrica na camada superficial do que o solo sob preparo convencional, oque, juntamente com a mel horia nas demais propriedades físicas do solo, pode ter contribuído para os maiores rendimentos acumulados de soja e milho naquele sistema de manejo.

\section{AGRADECIMENTOS}

À Cooperativa Agrária, pela manutenção, condução e financiamento do experimento desde a instalação até o presente momento. Ao Engㅇ. Agro. Sr. Franz J aster, pela instalação e realização do experimento na sua fase inicial, cuja iniciativa pioneira representou grande contribuição para o avanço do entendimento e adoção de sistemas conservacionistas de manejo do solo noSul doBrasil.

\section{LITE RATURA CITADA}

ABRÃO, P.U.R.; GOEPFERT, C.F.; GUERRA, M.; ELTZ, F.L.F. \& CASSOL, E.A. Efeitos de sistemas de preparo do solo sobre características de um Latossolo Roxo distrófico. R. Bras. Ci. Solo, 3:169-172, 1979.

ALBUQUERQUE, J .A.; REINERT, D.J . \& FIORIN, J.E. Variação temporal da estabilidade estrutural em Podzólico Vermelho-Amarelo. Ci. Rural, 24:275-280, 1994.

ALBUQUERQUE, J.A.; REINERT, D.J .; FIORIN, J.E.; RUEDELL, J. PETRERE, C. \& FONTINELLI, F. Rotação de culturas e sistemas de manejo do solo: efeito sobre a forma da estrutura do solo ao final de sete anos. R. Bras. Ci. Solo, 19:115-119, 1995.

BERTOL, I.; SCHICK, J .; MASSARIOL, J .M.; REIS, E.F. \& DILY, L. Propriedades físicas de um Cambissolo Húmico álico afetadas pelo manejo do solo. Ci. Rural, 30:91-95, 2000. 
BLAKE, G.R. \& HARTGE, K.H. Bulk density. In: KLUTE, A., ed. Methods of soil analisys. 2.ed. Madison, American Society of Agronomy, 1986. p.363-375.

BRADFORD, J .M. Penetrability. In: KLUTE, A., ed. Methods of soil analysis. 2.ed. Madison, American Society of Agronomy, 1986. p.463-477.

BRAGAGNOLO, N. \& MIELNICZUK, J . Cobertura do solo por palha de trigo s seu relacionamento com a temperatura e umidade do solo. R. Bras. Ci. Solo, 14:369-374, 1990.

CAMPOS, R.C.; REINERT, D.J .; NICOLODI, R.; RUEDELL, J . \& PETRERE, C. Estabilidade estrutural de um Latossolo Vermelho-Escuro distrófico após sete anos de rotação de culturas e sistemas de manejo do solo. R. Bras. Ci. Solo, 19:121-126, 1995.

CARPENEDO, V. \& MIELNICZUK, J. Estado de agregação e qualidade de agregados de $L$ atossol os Roxos, submetidos a diferentes sistemas de manejo. R. Bras. Ci. Solo, 14:99105, 1990.

CIOTTA, M.N. Componentes da acidez do solo e calagem superficial em um Latossolo Bruno alumínico sob plantio direto há 20 anos. Lages, U niversidade do Estado de Santa Catarina, 2001. 100p. (Tese de Mestrado)

COSTA, F.S. Propriedades físicas e produtividade de culturas de um Latossolo Bruno sob sistemas de manejo em experimento de longa duração. Lages, Universidade do Estado de Santa Catarina, 2001. 98p. (Tese de Mestrado)

DE BOER, W. \& KOWALCHUK, G.A. Nitrification in acid soils: micro-organisms and mechanisms. Soil Biol. Biochem., 33:853-866, 2001.

DEXTER, A.R. Advances in characterization of soil structure. Soil Till. Res., 11:199-238, 1988.

DORAN, J.W. \& PARKIN, T.B. Defining and assessing soil quality. In: DORAN, J.W., COLEMAN, D.C., BEZDICEK, D.F. \& STEWART, B.A., eds. Defining soil quality for a sustainable environment. Madison, Soil Science Society of America, 1994. p.3-21. (Special publication, 35)

ELTZ, F.L.P.; PEIXOTO, R.T.G. \& J ASTER, F. Efeitos de sistemas de preparo do solo nas propriedades físicas e químicas de um Latossolo Bruno álico. R. Bras. Ci. Solo, 13:259-267, 1989.

EMPRESA BRASILEIRA DE PESQUISA AGROPECUÁRIA EMBRAPA. Centro Nacional de Pesquisa de Solos. Manual de métodos de análise de solo. 2.ed. Rio de J aneiro, 1997. $212 p$.

EMPRESA BRASILEIRA DE PESQUISA AGROPECUÁRIA EMBRAPA. CentroNacional de Pesquisa de Solos. Sistema Brasileiro de Classificação de Solos. Brasília, 1999. 412p.

GUPTA, S.C.; SHARMA, P.P. \& DEFRANCHI, S.A. Compaction effects on soil structure. Adv. Agron., 42:311-338, 1989.

HILLEL, D. Environmental soil physics. San Diego, Academic Press, 1998. p.309-339.
HU, S.; COLEMAN, D.C.; CARROL, C.R.; HENDRIX, P.F. \& BEARE, M.H. Labile soil carbon pools in subtropical forest and agricultural ecosystems as influenced by management practices and vegetation types. Agric. Ecosys. Environ., 65:69-78, 1997

J ACKSON, R.D. \& TAYLOR, S.A. Thermal conductivity and diffusivity: laboratory methods. In: KLUTE, A., ed. Methods of soil analysis. Part 1. 2.ed. Madison, American Society of Agronomy, 1986. p.945-955.

J ASTER, F.; ELTZ, F.L.F.; FERNANDES, F.F.; MERTEN, G.H.; GAUDÊNCIO, C.A. \& OLIVEIRA, M.C.N. Rendimento de grãos em diferentes sistemas de preparo e manejo de solos. Londrina, Empresa Brasileira de Pesquisa Agropecuária Centro Nacional de Pesquisa de Soja, 1993. 37p. (Documentos, 61)

KEMPER, W.D. \& CHEPIL, W.S. Sizedistribution of aggregates. In: BLACK, C.A.; EVANS, D.D.; WHITE, J .L., eds. Methods fo soil analysis. Madison, American Society of Agronomy, 1965. p.499-510.

KLUTE, A. \& DIRKSEN, C. Hydraulic conductivity and diffusivity: laboratory methods. In: KLUTE, A., ed. Methods of soil analysis. Part 1. 2.ed. Madison, American Society of Agronomy, 1986. p.687-732.

MAACK, R. Notas preliminares sobre clima, solos e vegetação do estado do Paraná. Arq. Biol. Tecnol., 2:102-200, 1948.

SALTON, J.C. \& MIELNICZUK, J. Relações entre sistemas de preparo, temperatura e umidade de um Podzólico Vermel ho-E scuro deEldorado do Sul (RS). R. Bras. Ci. Solo, 19:313-319, 1995.

SEYBOLD, C.A.; HERRICK,J .E. \& BREJ DA, J J . Soil resilience: a fundamental component of soil quality. Soil Sci., 164:224234, 1999.

SIDIRAS, N.; VIEIRA, S.R. \& ROTH, C.H. Determinação de algumas características físicas de um Latossolo Roxo distrófico sob plantio direto e preparo convencional. R. Bras. Ci. Solo, 8:265-268, 1984

SILVA, I.F. \& MIELNICZUK, J. Ação do sistema radicular de plantas na formação e estabilização de agregados do solo. R. Bras. Ci. Solo, 21:113-117, 1997.

TORMENA, C.A.; ROLOFF, G. \& SÁ, J.C.M. Propriedades físicas do sol o sob plantio direto influenciadas por calagem, preparoinicial etráfego. R. Bras. Ci. Solo, 22:301-309, 1998.

VAN ES, H.M.; OGDEN, C.B.; HILL, R.L.; SCHINDELBECK, R.R. \& TSEGAYE, T. Integrated assessment of space, time, and management-related variability of soil hydraulic properties. Soil Sci. Soc. Am. J ., 63:1599-1608, 1999.

VOMOCIL, J.A. \& FLOCKER, W.J . Effect of soil compaction on storage and movement of soil air and water. Trans. Am. Soc. Agric. Eng., 4:242-246, 1961. 